\title{
Analysis of Dimensional Variations of Precision Gear Forging Die Geometry Due to Shrink Fit
}

\author{
Prof. Dr. Omer Eyercioglu \\ Gaziantep University, Faculty of Engineering, \\ Mech. Eng. Dept., Gaziantep, Turkey
}

\section{Abstract}

The usual way to shrink fit design for precision forging dies are made by thick wall cylinder approach; i.e., taking the pitch diameter of the gear as bore diameter of the die insert without considering gear tooth shape. However, the compressive pre-stress due to the shrink fitting causes dimensional variations on the gear profile of the die insert. The dimensional accuracy of the final product is dependent on the accuracy of the gear die. Therefore, the dimensional variations due to shrink fit must be pre-determined and the gear tooth profile on the die insert modified accordingly. In this study, the dimensional variations of the precision spur gear forging die because of shrink fitting are analyzed by finite element method and the results are compared with the experimental ones. The results show that the FE model is successful to simulate the cylindrical die and agree well with thick wall cylinder approach and the experimental measurements. However, both the experimental measurements and the finite element results of gear die predict much higher radial displacements than the results of cylindrical die. Therefore, the determination of shape change of the gear die profile is beyond the capability of the thick wall cylindrical approach.

Keywords: Precision Gear Forging, Die Design, Shrink Fit, Finite Element

\section{Introduction}

The technology of precision forging has attained great commercial success in recent years. The major application is the forging of gears for high volume commercial sectors such as automobile and truck transmissions (Behrens BA, 2007). The process has been successively applied for straight and spiral bevel gears at first then spur and helical gears have been forged with functional surfaces which can be finished in one operation (Eyercioglu 0, 1996, Dean TA, 2000). The current studies are focused on increasing the quality of the precision forged gears for high quality gear transmission applications such as turboprop gearboxes (Eyercioglu, 0, 2018). One of the important problems in precision gear forging is the dimensional change of the die components during forging. They subjected to high loads in a very short period of time and should withstand to high 
static and impact pressures, friction forces between surfaces, and both mechanical and thermal fatigue (Yilmaz. NF and Eyercioglu 0, 2018).

As an engineering practice, the die insert is shrunk fit into one or more shrink rings in order to increase the resistance of the die insert against forging pressure. A compressive hoop (tangential) pre-stress on the die insert is created by interference between mating diameters of adjacent rings. The compressive hoop stress imposed by shrink ring has a cumulative effect at the bore of the die insert. Consequently resultant tensile hoop stress on the bore, caused by the forging loads can be substantially reduced. The usual way to calculate the interference allowance between the die insert and the shrink ring is to use thick wall cylinder approach (Parsons and Cole, 1968). The approach is given in detail by Lame (1852). This approach is also used for design of precision spur gear forging dies (Eyercioglu 0 and Dean TA, 1997) by considering the die assembly as a short cylinder if the facewidth of the gear is not too long. In this case, the die is considered as a cylinder with an inside (bore) diameter equal to the pitch circle of the gear and the actual gear tooth shape is neglected.

However, the compressive pre-stress due to the shrink fitting causes dimensional variations on the gear profile of the die insert. The dimensional accuracy of the final product is dependent on the accuracy of the gear die. Therefore, the dimensional variations due to shrink fit must be pre-determined and the gear tooth profile on the die insert modified accordingly. For this purpose many researcher have been worked on the dimensional accuracy of the gear forging dies (Eyercioglu 0 1994, Sadeghi MH 2003, Yilmaz NF, 2009, Eyercioglu, O. 2009). Pederson (2006) suggest two methods (classical plane analysis and a super element technique) to obtain a direct solution without iteration to determine the shape of a shrink fit surface result in a prescribed distribution of contact pressure due to the shrink fit. A theoretical model is presented for predicting involute profile deflection in hot precision forging of gears was presented by Zuo (2017).

In this study, the dimensional variations of the precision spur gear forging die because of shrink fitting are analyzed by finite element (FE) method and the results are compared with the experimental ones. The FE model is verified with thick wall cylinder approach and the experimental results for cylindrical die.

\section{Shrink Fit Design}

The thick wall cylinder equations formulated by Lame (1852) are generally used in most shrink fit applications. The interference pressure $(p)$ between die and the ring due to shrink fitting in terms of radial interference, $(z)$, is given as: 

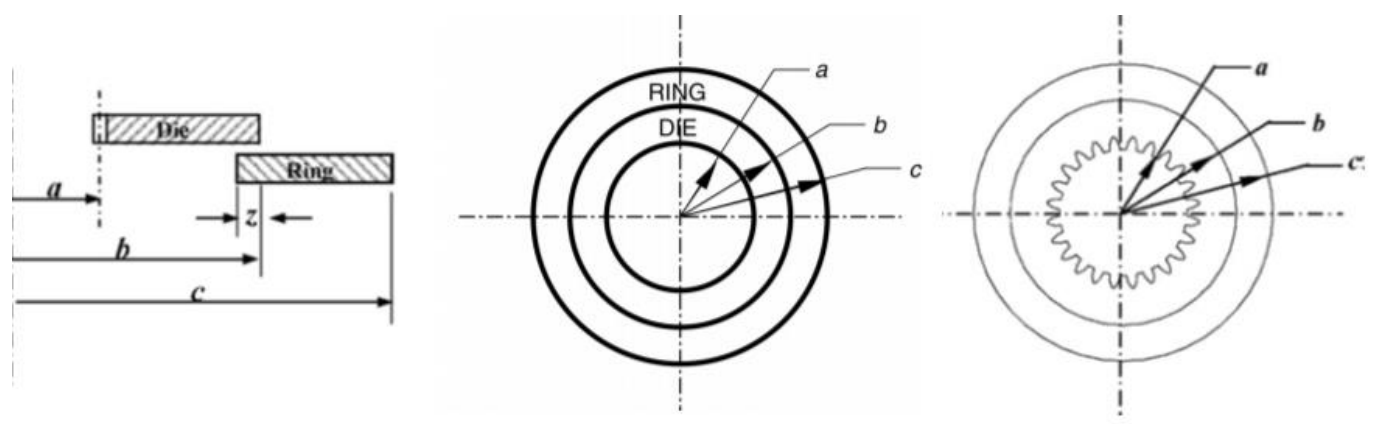

Figure 1. Shrink fit models for cylindrical and gear dies

$p=\frac{E z\left(b^{2}-a^{2}\right)\left(c^{2}-b^{2}\right)}{2 b^{3}\left(c^{2}-a^{2}\right)}$

(1)

where $(E)$ Young's Modulus, $(a)$ and $(b)$ are the inner and outer diameter of the die insert, respectively. The die insert that is shrink fitted by the ring, seen in figure 1 , is exposed to an external pressure $p$ due to the shrink-fit between die and ring. The tangential (hoop) $\left(\sigma_{t}\right)$ and radial stresses $\left(\sigma_{r}\right)$ on the die insert can be calculates as:

$\sigma_{t}=-\frac{p b^{2}}{b^{2}-a^{2}}\left(1+\frac{a^{2}}{r^{2}}\right)$

(2)

$\sigma_{r}=-\frac{p b^{2}}{b^{2}-a^{2}}\left(1-\frac{a^{2}}{r^{2}}\right)$

(3)

and the radial displacement $\left(u_{d}\right)$ is given as:

$u_{d}=-\frac{p b^{2}}{E\left(b^{2}-a^{2}\right)}\left[(1-v) r+(1+v) \frac{a^{2}}{r}\right]$

(4)

here the variable $r$ varies between limits $a$ and $b$, and $(v)$ is Poisson's ratio.

Similar equations can be used for the ring can be for the stresses and the radial deflections $\left(u_{r}\right)$ of the ring are written as: (where $r$ varies now between $b$ and $c$ ) 


$$
\sigma_{t}=\frac{p b^{2}}{c^{2}-b^{2}}\left(1+\frac{c^{2}}{r^{2}}\right)
$$

(5)

$$
\sigma_{r}=\frac{p b^{2}}{c^{2}-b^{2}}\left(1-\frac{c^{2}}{r^{2}}\right)
$$

(6)

$$
u_{r}=\frac{p b^{2}}{E\left(c^{2}-b^{2}\right)}\left[(1-v) r+(1+v) \frac{c^{2}}{r}\right]
$$

The optimised values of $(b, c, z)$ are determined based on the procedures given in Handbook of Metal Forming (Lange K, 1985). For a known die inner radius $a$, radial interference $z$, die outside radius $b$ and ring outside radius $c$ are given as:

$$
z=\frac{b \cdot S_{y}}{\mathrm{E}}\left(\frac{1}{K_{1}}-Q_{1}^{2}\right)
$$

$b=a / Q_{1}$

$c=a / \mathrm{Q}$

where;

$\mathrm{Q}_{1}=\sqrt{\frac{1}{2}\left(1+\frac{1}{K_{1}}\right)-p^{\prime}}$

$$
\mathrm{Q}_{2}=\mathrm{Q}_{1} \sqrt{K_{1}}
$$

$\mathrm{Q}=\mathrm{Q}_{1} \mathrm{Q}_{2}$

$p^{\prime}=\mathrm{p}_{\mathrm{i}} / \mathrm{S}_{\mathrm{y}}$

$$
K_{1}=\mathrm{S}_{\mathrm{y}(\text { ring) }} / \mathrm{S}_{\mathrm{y} \text { (die) }}
$$


here $(S y)$ is the yield strength.

In the case of gear forging die, the shrink fitting is designed based thick wall cylindrical approach by considering the pitch diameter of the gear is the inner diameter of the die insert. Therefore, the Equations 8-15 are used however, it may be expected that the profile of the gear tooth may cause stress concentrations on the inside surface of the die.

\section{Experimental Procedure}

\section{Forging Gear Die}

The gear in the study is a $3 \mathrm{~mm}$ module $(\mathrm{m}), 28$ teeth $(N)$ and $20^{\circ}$ pressure angle standard spur gear (i. e. addendum is equal to module and the dedendum is 1.25 times module). The corresponding pitch diameter is equal to $84 \mathrm{~mm}(\mathrm{a}=42 \mathrm{~mm})$. The height of the inner die and the outer ring is selected as $50 \mathrm{~mm}$. The internal pressure encountered during precision forging of the gear used in this study was taken as $620 \mathrm{MPa}$ from the previous study of the author (Eyercioglu 0, 2018). The corresponding die geometry parameters $(b, c$ and $z$ ) were calculated by using Equations 8-15 and shown in Table 1. For validating the analytical, simulation (FEM) and experimental results a cylindrical die having $42 \mathrm{~mm}$ bore radius was also manufactured. The gear die assembly is given in figure 2 .

\section{Table 1. The die geometry parameters}

\begin{tabular}{|l|l|l|l|l|l|l|l|l|l|}
\hline $\begin{array}{l}m \\
(\mathrm{~mm})\end{array}$ & $N$ & $E(\mathrm{GPa})$ & $\begin{array}{l}\text { Sy } \\
(\mathrm{MPa})\end{array}$ & $v$ & $\begin{array}{l}p \\
(\mathrm{MPa})\end{array}$ & $a(\mathrm{~mm})$ & $\begin{array}{l}b \\
(\mathrm{~mm})\end{array}$ & $\begin{array}{l}c \\
(\mathrm{~mm})\end{array}$ & $\begin{array}{l}z \\
(\mathrm{~mm})\end{array}$ \\
\hline 3 & 28 & 210 & 1030 & 0.3 & 133 & 42 & 66.42 & 105.05 & 0.2 \\
\hline
\end{tabular}

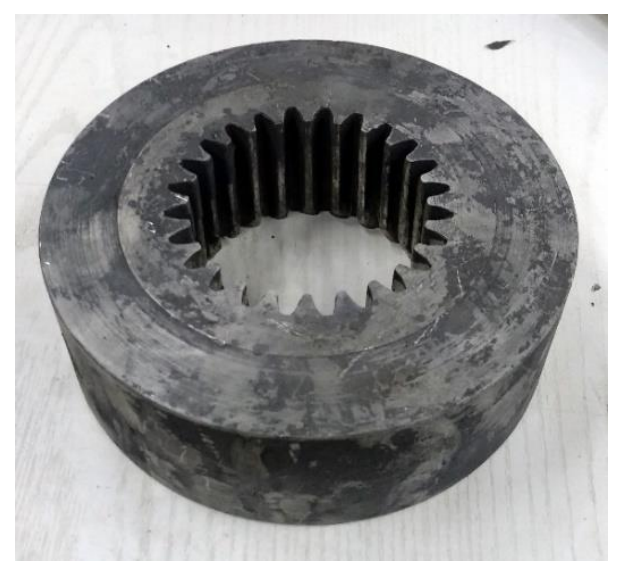

Figure 2. The gear die assembly

\section{Die Material, Manufacturing and Shrink Fitting}

AISI H13 hot work tool steel was used for inner die and the outer ring materials. The die components are hardened and tempered to obtain 52-55 HRC. The cylindrical inner die 
and the outer rings for cylindrical and gear dies are machined to required diameters using a CNC lathe and grinding machine in the accuracy of $\pm 0.01 \mathrm{~mm}$. The gear tooth profile was cut by using wire electro discharge machine (WEDM). The inner die and the outer ring were shrunk by cooling the inner die in liquid nitrogen and heating the outer ring to a temperature of about $200^{\circ} \mathrm{C}$.

\section{Profile Measurements}

The dimensions of the die components and the gear profile before and after shrink fitting were measured by Kemco 3D Coordinate Measuring Machine (CMM) using a $1 \mathrm{~mm}$ ruby touch probe of Renishaw. The measurements repeated at least three times to ensure the results.

\section{Finite Element Modeling}

For the gear die, a 3D single tooth a model was created in SolidWorks and exported to Simufact Forming FE package. The generated mesh type and the number of elements were tetrahedral and 180000 , respectively. Symmetry plane boundary condition applied to the both side of the model. A uniform friction (0.2) and interference $\mathrm{z}=0.2 \mathrm{~mm}$ was applied between the die and the ring. The cylindrical die model was created similarly. The 3D FE models of the gear and cylindrical dies are shown figure 3.
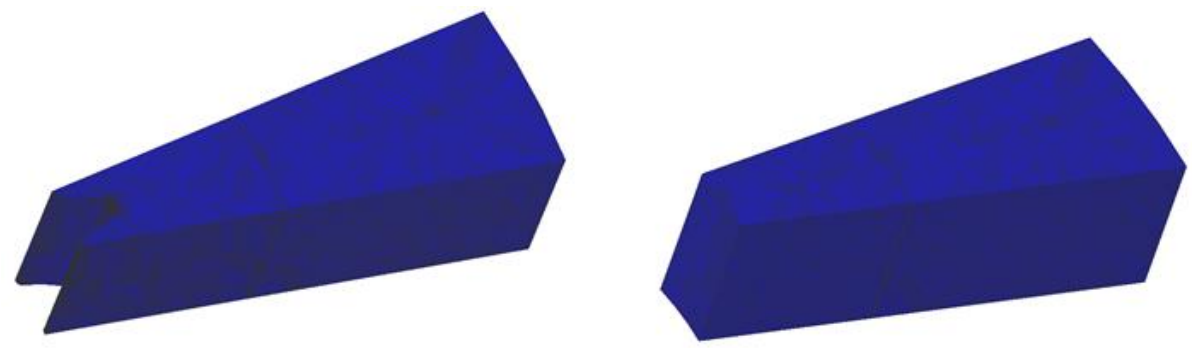

Figure 3. 3D FE models of the gear and cylindrical dies.

\section{Results and Discussion}

\section{The Cylindrical Die}

The radial displacement (contraction) of the inner die bore radius is calculated as $0.0886 \mathrm{~mm}$ by using equation 4 . The finite element results (see figure 4 ) and the 3D CMM measurements given in Table 2 are in well agreement with the analytical one. The 3D CMM measurements of the inner die radius is scattering between $41.909 \mathrm{~mm}$ to 41.914 $\mathrm{mm}$, the corresponding radial displacement is in between -0.091 to $-0.086 \mathrm{~mm}$. The FE results show a uniform distribution over inner surface with a radial displacement value of $-0.0879 \mathrm{~mm}$. The slight differences among analytical, CMM and FEM are coming from the nature of the measurement and truncated values during re-meshing. These results 
show that the FE model is successful to simulate the thick wall cylinder approach and it is validated with the experimental ones (CMM).

\section{Radial displacement [mm]}

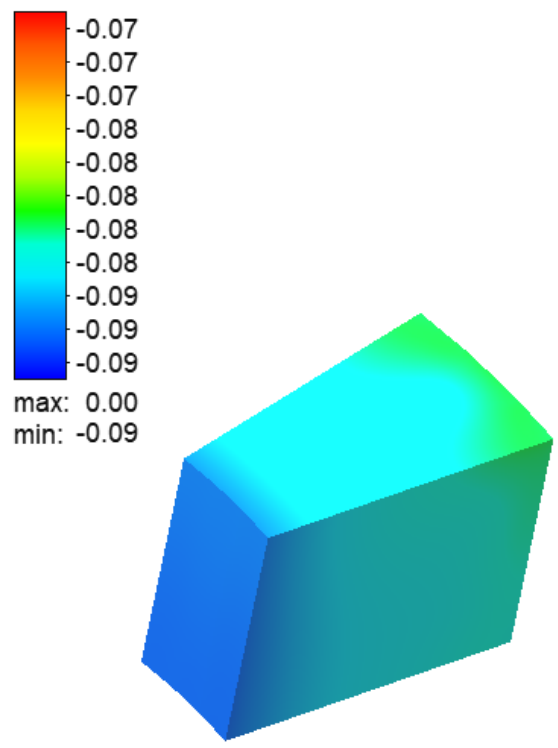

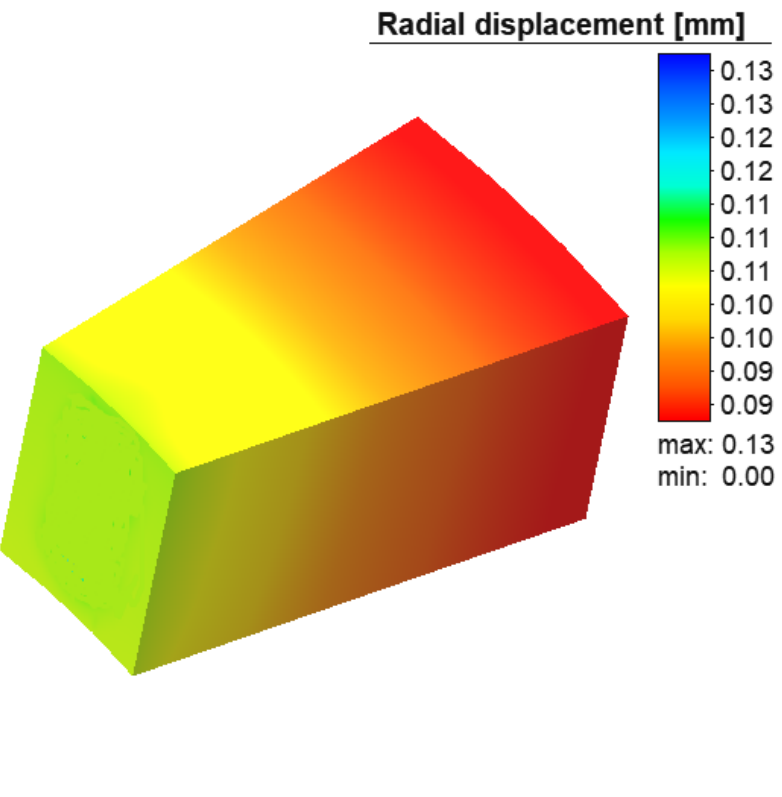

Figure 4. FE results of cylindrical die.

\section{The Gear Die}

The radial distance $(r)$ and the corresponding radial displacement $\left(u_{r}\right)$ of the gear profile are given in Table 2. The radial displacement calculated from 3D CMM measurements is scattering between $-0.105 \mathrm{~mm}$ to $-0.114 \mathrm{~mm}$. The FE result shows a uniform distribution over inner surface with a radial displacement value of $-0.110 \mathrm{~mm}$ as shown in figure 5 and Table 2. The CMM and FE results are in well agreement. However, both the experimental (CMM) and the finite element results of gear die predict much higher radial displacements than the results of cylindrical die $(-0.0886 \mathrm{~mm})$. Therefore, the shape change of the gear die profile is beyond the capability of the thick wall cylindrical approach. The gear profiles measured by CMM before and after shrink fit are shown in figure 6. In the design of gear forging die, the gear tooth profile have to be modified before cutting according to obtain the standard gear after shrink fitting. This can be done by adding radial displacement due to shrink fit on the radial distance of tooth profile $(r$ $+u_{r}$ ). 


\section{Radial displacement [mm]}
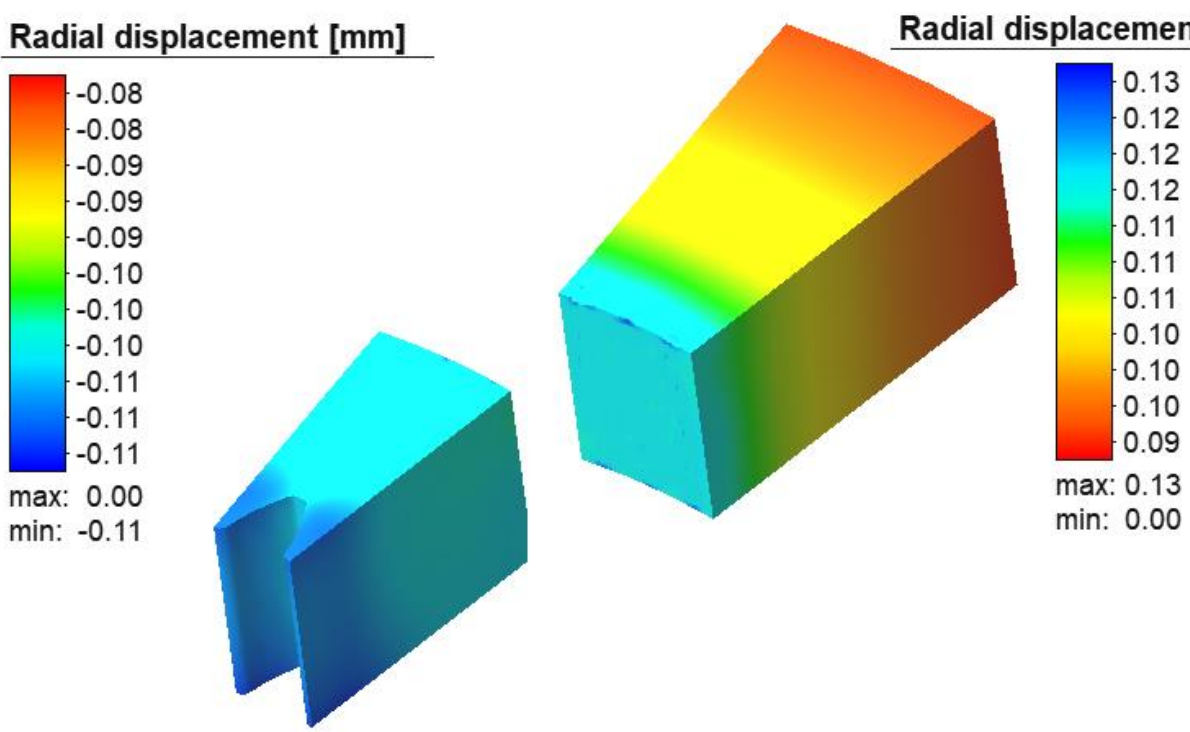

Figure 5. FE results of gear die

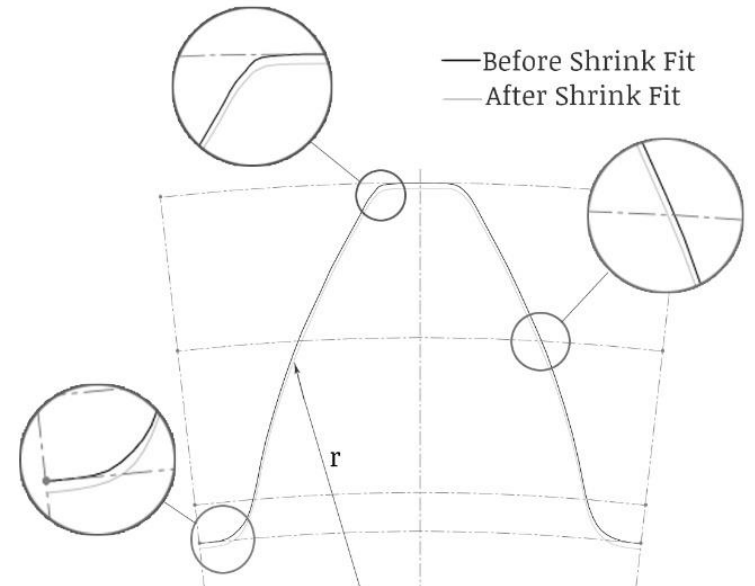

Figure 6. Gear tooth profile before and after shrink fitting.

Table 2. Radial displacement of the inner surfaces

\begin{tabular}{|l|l|l|l|l|l|}
\hline \multicolumn{2}{|l|}{ Clylindrical Die } & \multicolumn{3}{l|}{ Gear Die } \\
\hline $\begin{array}{l}\text { a CMM } \\
(\mathrm{mm})\end{array}$ & $\begin{array}{l}u_{r} \text { CMM } \\
(\mathrm{mm})\end{array}$ & $\begin{array}{l}u_{r} \text { FEM } \\
(\mathrm{mm})\end{array}$ & $\begin{array}{l}\text { r } \\
(\mathrm{mm})\end{array}$ & $\begin{array}{l}u_{r} \text { CMM } \\
(\mathrm{mm})\end{array}$ & $\begin{array}{l}u_{r} \text { FEM } \\
(\mathrm{mm})\end{array}$ \\
\hline 41,912 & $-0,088$ & $-0,088$ & 38,152 & $-0,105$ & $-0,110$ \\
\hline 41,912 & $-0,088$ & $-0,088$ & 38,158 & $-0,107$ & $-0,110$ \\
\hline 41,911 & $-0,089$ & $-0,088$ & 38,197 & $-0,108$ & $-0,110$ \\
\hline
\end{tabular}




\begin{tabular}{|l|l|l|l|l|l|}
41,914 & $-0,086$ & $-0,088$ & 38,279 & $-0,113$ & $-0,110$ \\
\hline 41,913 & $-0,087$ & $-0,088$ & 38,487 & $-0,106$ & $-0,110$ \\
\hline 41,911 & $-0,089$ & $-0,088$ & 38,850 & $-0,107$ & $-0,110$ \\
\hline 41,911 & $-0,089$ & $-0,088$ & 39,298 & $-0,114$ & $-0,110$ \\
\hline 41,913 & $-0,087$ & $-0,088$ & 39,780 & $-0,113$ & $-0,110$ \\
\hline 41,911 & $-0,089$ & $-0,088$ & 40,247 & $-0,108$ & $-0,110$ \\
\hline 41,910 & $-0,086$ & $-0,088$ & 40,709 & $-0,111$ & $-0,110$ \\
\hline 41,914 & $-0,09$ & $-0,088$ & 41,160 & $-0,114$ & $-0,110$ \\
\hline 41,911 & $-0,086$ & $-0,088$ & 41,610 & $-0,113$ & $-0,110$ \\
\hline 41,912 & $-0,089$ & $-0,088$ & 42,051 & $-0,111$ & $-0,110$ \\
\hline 41,913 & $-0,088$ & $-0,088$ & 42,474 & $-0,111$ & $-0,110$ \\
\hline 41,910 & $-0,087$ & $-0,088$ & 42,893 & $-0,106$ & $-0,110$ \\
\hline 41,912 & $-0,09$ & $-0,088$ & 43,281 & $-0,113$ & $-0,110$ \\
\hline 41,909 & $-0,088$ & $-0,088$ & 43,639 & $-0,112$ & $-0,110$ \\
\hline 41,913 & $-0,091$ & $-0,088$ & 43,949 & $-0,108$ & $-0,110$ \\
\hline 41,912 & $-0,087$ & $-0,088$ & 44,192 & $-0,111$ & $-0,110$ \\
\hline 41,911 & $-0,088$ & $-0,088$ & 44,409 & $-0,109$ & $-0,110$ \\
\hline 41,912 & $-0,089$ & $-0,088$ & 44,589 & $-0,105$ & $-0,110$ \\
\hline 41,912 & $-0,088$ & $-0,088$ & 44,725 & $-0,112$ & $-0,110$ \\
\hline 41,911 & $-0,088$ & $-0,088$ & 44,834 & $-0,106$ & $-0,110$ \\
\hline 41,912 & $-0,089$ & $-0,088$ & 44,884 & $-0,109$ & $-0,110$ \\
\hline 41,913 & $-0,088$ & $-0,088$ & 44,892 & $-0,107$ & $-0,110$ \\
\hline 41,910 & $-0,09$ & $-0,088$ & 44,893 & $-0,105$ & $-0,110$ \\
\hline
\end{tabular}

\section{Conclusions}

In general practice, shrink fit design for precision forging dies are made by thick wall cylinder approach; i.e., taking the pitch diameter of the gear as bore diameter of the die insert without considering gear tooth shape. However, the compressive pre-stress due to the shrink fitting causes dimensional variations on the gear profile of the die insert. The amount of radial displacement of the gear tooth profile must be predetermined and the profile has to be modified accordingly to manufacture the forged gear in required accuracy. The followings can be concluded from the analytical calculations, experimental work and FE analyses performed in this study:

For cylindrical die insert, the experimental results (CMM measurements) show that the thick wall cylinder approach formulated by Lame well predicts the radial displacement of the inner die radius.

The FE model is successful to simulate the cylindrical die and agree well with thick wall cylinder approach and the experimental ones (CMM).

Both the experimental (CMM) and the finite element results of gear die predict much higher radial displacements than the results of cylindrical die. Therefore, the determination of shape change of the gear die profile is beyond the capability of the thick wall cylindrical approach. 


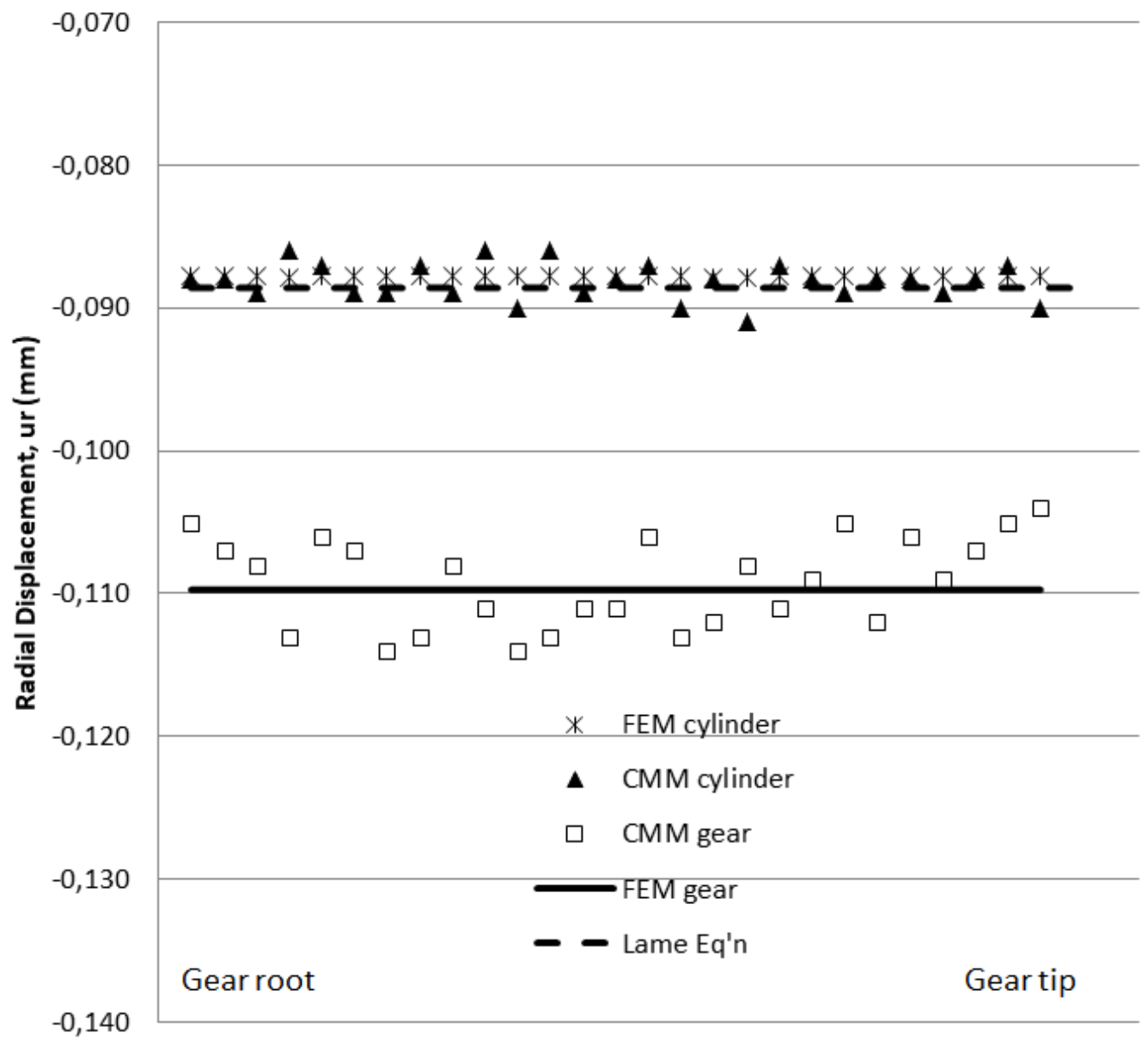

\section{Acknowledgements}

The author would like to thank The Scientific and Technological Research Council of Turkey (Tubitak Grand No: MAG-217M063) and BAPYB of Gaziantep University for their financial supports.

\section{References}

[1] Behrens BA, Doege E, Reinsch S, Telkamp K, Daehndel H, Specker A, (2007) Precision forging processes for high-duty automotive components. J Mater Proc Tech 185:139146.

[2] Dean TA (2000) The Net-Shape Forming of Gears. Mater Des 21:271-278.

[3] Eyercioglu, O., Dean, T. A. and Walton, D. (1994) Dimensional accuracy of hot precision forged spur gears. In 1994 International Gearing Conference, Newcastle Upon Tyne, pp. 285-290. 
[4] Eyercioglu O, Dean TA, Walton D, (1996) "Precision Forging of Gears," presented at the 7th Int. Machine Design and Production Conference, Ankara, Turkey.

[5] Eyercioglu, 0. and Dean, T. A. (1997) Design and manufacture of precision gear forging dies. In CIRP International Conference on Design and Production of Dies and Molds, Istanbul, Turkey, pp. 311-316.

[6] Eyercioglu,O., Kutuk, M. A. and Yilmaz, N. F.(2009) Shrink fit design for precision gear forging dies, Journal of Materials Processing Technology, vol. 209, no. 4, pp. 2186-2194.

[7] Eyercioglu O. (2018) Precision Forging of Asymmetric Spur Gears, Tubitak-MAG $217 \mathrm{M} 063$.

[8] Lame, G., (1852). Lecons sur la Theorie Mathematique del Elasticite des Corps Solides, Bachelier, Paris, Septieme Lecon.

[9] Lange, K., (1985) Handbook of Metal Forming. McGraw-Hill, New York, pp. 15-88.

[10] Parsons, B., Cole, B.N., (1968). A generalized approach to the optimum design of short composite cylinders, Proc. Inst. Mech. Eng. 182.

[11] Pederson, P. (2006) On Shrink Fit Analysis and Design Comput Mech (2006) 37: 121-130 DOI 10.1007/s00466-005-0664-7

[12] Sadeghi MH (2003) Gear forging: mathematical modeling and experimental validation. J Manuf Sci E-T ASME 125:753-762

[13] Yilmaz NF, Eyercioglu O (2009) An integrated computer-aided decision support system for die stresses and dimensional accuracy of precision forging dies. Int J Adv Manuf Technol 40:875-886.

[14] Yilmaz. N. F. and Eyercioglu, O., (2018) Near Net Shape Spur Gear Forging Using Concave Preform, MECHANIKA. 2018 Volume 24(2): 268-277.

[15] Zuo B., Wang, B., Li, Z., Li, N., and Lin, J., An investigation of involute and lead deflection in hot precision forging of gears Int J Adv Manuf Technol (2017) 88:30173030 DOI 10.1007/s00170-016-9003-8. 